ing week, a week in the university vacation and a week falling within an examination period. The object is to enable the University Grants Commission to estimate teaching and research costs, subject by subject, for individual universities. Expenditure on academic salaries accounts for about half the recurrent expenditure on universities, and the Committee of Vice-Chancellors says that correct allocation of salary costs between undergraduate teaching, postgraduate teaching and research is essential in any attribution of costs. It seems that the UGC is hoping to find out the relative costs in different universities of producing the same or similar first-degree output, and it hopes that the survey will provide an additional tool for assessing the recurrent needs of the universities.

Academic staff are being asked to record the time spent in seven different activities: "undergraduate time", including teaching and associated activities; "graduate course work time", that spent in teaching higher degree courses where the emphasis is on instruction rather than on research; "graduate research time", including all forms of supervision, project assistance and research training; "personal research time"; "unallocable internal time" which, despite the graphic description, includes reading, study, discussion and conferences; "external professional time", which includes consultancy, industrial projects, committee work and outside lecturing; and "private and free time", including eating (provided, of course, that nobody talks shop), sleeping, family contacts as they are called and community work not related to professional status-for example, says the Committee of Vice-Chancellors, being a churchwarden.

The survey, which will be conducted once in a quin. quennium, has provoked criticism and ridicule from several teachers. Chief among the criticisms seems to be the difficulties involved in allocating time spent in such activities as discussion and formulating ideas. Underlying these criticisms, however, is undoubtedly a feeling of indignation that the daily activities of academics should be subjected to time and motion studies.

\section{ATOMIC ENERGY}

\section{Is Euratom Saved?}

LAST Saturday's resolutions passed by the European Economic Community's Council of Ministers of Science and Technology have at long last lifted Euratom off the floor, even if they have not put it back on its feet. For far too long now-since 1967-Euratom has been living a hand-to-mouth existence, making do with research budgets approved on a twelve-month basis, and this year on a six-month basis, instead of the grand five year programmes which the organization has been accustomed to. It is true, of course, that what took place in Brussels at the weekend is in fact a holding operation, but the long-suffering staff of Euratom will be glad that their jobs seem to be assured for a couple of years at least.

The resolution passed by the council fixes the 1970 budget at $\$ 53$ million, with a continuation into 1971 on the understanding that, from 1970 onwards, the organization will promote wider cooperation throughout the community on advanced reactors. It also asks for a restructuring of the Euratom management so that it becomes a more effective machine for co- operation between member states. Other parts of the resolution allow the common research centre which is so far confined to nuclear activities to do non-nuclear work. In particular this seems to be to allow the centre to take up what projects out of the Aigrain proposals the community decides on. The centre will also be allowed to do work under contract for individual companies. Finally, the council has said that a decision on the long-term supply of uranium will be taken next year, when there will have been a chance to look at the rival merits of a pilot plant in France and the centrifuge process.

What seems to have inspired the ministers to release Euratom from the impasse are the signs of a new spirit of cooperation which arose out of the recent summit meeting of the community at The Hague. Without this, the staff of Euratom might still have been in their previous demoralizing situation. Although the resolution was as likely as not taken for political reasons, possibly with the notion of being in a position to get as much technological benefit out of British entry as possible, the result is that people are more optimistic about the future of Euratom than they have been for years. It now remains to be seen what interpretation the community summit places on the resolutions.

\section{CONSERVATION}

\section{Plans for Europe}

Conferences, competitions, special postage stamps, film festivals, a youth parliament and Viking beacons will be some of the features of European Conservation Year, to be launched in the United Kingdom in the traditional way with a dinner at the Guildhall, London, on December 16. Twenty-five countries are involved in this concerted effort to communicate the need to stop spreading fear and gloom and to do something about pressures on the environment.

The highlight of the year seems likely to be the gathering of top people, including Mr Anthony Crosland, the Secretary of State for Regional Government and Planning, at the European Conservation Conference in Strasbourg next February. Later in the year there will be a large international congress in London organized by the World Wildlife Fund.

The Netherlands will have a conservation fleet and Germany a State Railways exhibition train to carry the good news from place to place. Italy is to have a film festival with a prize of a million lire for the best film on conservation, and four Scandinavian countries will light Viking warning pyres every ten miles along two thousand miles of coast; it is to be hoped that they do no harm to the environment. The youth parliament will be in Stockholm, where the Prime Minister will join the young delegates.

Special stamps are to be issued by at least fifteen of the participating countries, and most of them will be organizing competitions for schools. In Britain the Nature Conservancy and the Shell organization are to run a competition for secondary school pupils, who will be encouraged to study local problems and suggest conservation projects. The winners, after competing in public for the final honours, will be taken on a tour of Europe at the expense of Shell.

British industry has been well roused to activity, and Kodak is joining with the Nature Conservancy to 